\title{
Analysis of the role of 13 major fimbrial subunits in colonisation of the chicken intestines by Salmonella enterica serovar Enteritidis reveals a role for a novel locus
}

Debra J Clayton*1, Alison J Bowen ${ }^{\dagger 1}$, Scott D Hulme ${ }^{\dagger 1,3}$, Anthony M Buckley1, Victoria L Deacon ${ }^{1}$, Nicholas R Thomson ${ }^{2}$, Paul A Barrow ${ }^{1,3}$, Eirwen Morgan ${ }^{1}$, Michael A Jones ${ }^{1,3}$, Michael Watson ${ }^{1}$ and Mark P Stevens ${ }^{1}$

\begin{abstract}
Address: ${ }^{1}$ Division of Microbiology, Institute for Animal Health, Compton, Berkshire, RG20 7NN, UK, ${ }^{2}$ Pathogen Genomics, Wellcome Trust Sanger Institute, Hinxton, Cambridge, CB10 1SA, UK and ${ }^{3}$ School of Veterinary Medicine and Science, University of Nottingham, Sutton Bonington, Leicestershire, LE12 5RD, UK

Email: Debra J Clayton* - debra.clayton@bbsrc.ac.uk; Alison J Bowen - alisonbowen9@hotmail.com; Scott D Hulme - scott.hulme@nottingham.ac.uk; Anthony M Buckley - tony.buckley@bbsrc.ac.uk;

Victoria L Deacon - victoria.deacon@bbsrc.ac.uk; Nicholas R Thomson - nrt@sanger.ac.uk; Paul A Barrow - paul.barrow@nottingham.ac.uk; Eirwen Morgan - eirwen.morgan@bbsrc.ac.uk; Michael A Jones - michael.a.jones@bbsrc.ac.uk; Michael Watson - michael.watson@bbsrc.ac.uk; Mark P Stevens - mark-p.stevens@bbsrc.ac.uk

* Corresponding author †Equal contributors
\end{abstract}

Published: 18 December 2008

BMC Microbiology 2008, 8:228 doi:10.1186/147/-2180-8-228
Received: 15 September 2008

Accepted: 18 December 2008

This article is available from: http://www.biomedcentral.com//47/-2/80/8/228

(c) 2008 Clayton et al; licensee BioMed Central Ltd.

This is an Open Access article distributed under the terms of the Creative Commons Attribution License (http://creativecommons.org/licenses/by/2.0), which permits unrestricted use, distribution, and reproduction in any medium, provided the original work is properly cited.

\begin{abstract}
Background: Salmonella enterica is a facultative intracellular pathogen of worldwide importance. Over 2,500 serovars exist and infections in humans and animals may produce a spectrum of symptoms from enteritis to typhoid depending on serovar- and host-specific factors. S. Enteritidis is the most prevalent non-typhoidal serovar isolated from humans with acute diarrhoeal illness in many countries. Human infections are frequently associated with direct or indirect contact with contaminated poultry meat or eggs owing to the ability of the organism to persist in the avian intestinal and reproductive tract. The molecular mechanisms underlying colonisation of poultry by $S$. Enteritidis are ill-defined. Targeted and genome-wide mutagenesis of $S$. Typhimurium has revealed conserved and host-specific roles for selected fimbriae in intestinal colonisation of different hosts. Here we report the first systematic analysis of each chromosomally-encoded major fimbrial subunit of $S$. Enteritidis in intestinal colonisation of chickens.

Results: The repertoire, organisation and sequence of the fimbrial operons within members of $S$. enterica were compared. No single fimbrial locus could be correlated with the differential virulence and host range of serovars by comparison of available genome sequences. Fimbrial operons were highly conserved among serovars in respect of gene number, order and sequence, with the exception of safA. Thirteen predicted major fimbrial subunit genes were separately inactivated by lambda Red recombinase-mediated linear recombination followed by P22/int transduction. The magnitude and duration of intestinal colonisation by mutant and parent strains was measured after oral inoculation of out-bred chickens. Whilst the majority of $S$. Enteritidis major fimbrial subunit genes played no significant role in colonisation of the avian intestines, mutations affecting pegA in
\end{abstract}


two different $S$. Enteritidis strains produced statistically significant attenuation. Plasmid-mediated trans-complementation partially restored the colonisation phenotype.

Conclusion: We describe the fimbrial gene repertoire of the predominant non-typhoidal $S$. enterica serovar affecting humans and the role played by each predicted major fimbrial subunit in intestinal colonisation of the primary reservoir. Our data support a role for PegA in the colonisation of poultry by $S$. Enteritidis and aid the design of improved vaccines.

\section{Background}

Non-typhoidal serovars of Salmonella enterica are an important cause of food-borne diarrhoeal illness in humans worldwide. Using active surveillance data from a catchment area of 44.5 million people, the FoodNet network has estimated that there are 1.4 million cases of human non-typhoid salmonellosis in the United States per annum, leading to 15,000 hospitalisations and 400 deaths [1]. Over the past three decades $S$. enterica serovar Enteritidis has emerged as a significant cause of such infections [2]. The consumption of undercooked poultry meat and eggs is a major risk factor for $S$. Enteritidis infection [3] and the phage types circulating in humans are commonly found in broilers [4] and layers [5]. The incidence of $S$. Enteritidis infection in humans declined markedly following the implementation of control strategies, including vaccination for poultry, regulations on storage and preparation of food and improved education [6]. Despite such measures, $S$. Enteritidis remains the most prevalent cause of non-typhoidal salmonellosis in many countries, including the United Kingdom http:// www.hpa.org.uk/infections/topics az/salmonella/

data.htm, and improved vaccines are needed to achieve further reductions in the burden of human disease.

It is well established that $S$. Enteritidis is able to persist in the intestinal and reproductive tract of poultry in the absence of clinical signs [7]; however the molecular mechanisms mediating colonisation of these sites are illdefined. Further, it is unclear why some S. enterica serovars are associated with enteric disease in a broad range of healthy out-bred adult hosts (e.g. Enteritidis and Typhimurium), whereas others are host-restricted or -specific and associated with severe systemic disease (e.g. Gallinarum in poultry and Typhi in humans). Targeted and genome-wide mutagenesis of the broad host range serovar Typhimurium has indicated that it uses both conserved and host-specific factors to colonise the intestines of chickens, cattle, pigs and mice [8-14]. Among the factors that influence intestinal colonisation are fimbriae; proteinaceous surface appendages that mediate interactions between bacteria and host cells.

Of the thirteen fimbrial loci predicted to be encoded by the $S$. Typhimurium genome, $l p f, f i m, b c f, s t b, s t c, s t d, s t h$ and csg have been implicated in virulence in mice $[11,13,15-17]$. Screening of a library of signature-tagged mutants of $S$. Typhimurium indicated that pathogenicity island (SPI)-6-encoded saf fimbriae may play a host-specific role in ileal colonisation of pigs [14], whereas the $s t b C, c s g D$ and $s t h B$ fimbrial genes were implicated in colonisation of the avian gut [12]. Separately Ledeboer et al described a role for $l p f A-E, p e f C, c s g A$ and $f i m H$, but not $s t h D$ or $b c f F$, in biofilm formation on chicken intestinal mucosa cultured ex vivo [18]. Relatively few studies have probed the role of fimbriae in colonisation of poultry by $S$. Enteritidis. Allen-Vercoe and Woodward reported that a $S$. Enteritidis mutant lacking fimD, $\operatorname{csg} A, p e f C, \operatorname{lpfC}$ and sefA colonised the caeca at comparable levels to the parent strain following oral dosing of 1 or 5 day-old chicks [19] and was similarly invasive [20] and adherent to chicken gut explants [21]. Furthermore, single mutants lacking fimA, csgA or sefA exhibited no significant defect in colonisation of chick caeca and were excreted in the faeces at comparable levels to the parent $[22,23]$. Although roles for $S$. Enteritidis fimbriae in intestinal colonisation of poultry have so far been lacking, Type I fimbriae [24] and curli [25] have been implicated in egg contamination.

In the recent publication of the complete genome sequence of $S$. Enteritidis strain P125019 [26] we have defined the full repertoire of fimbrial loci and identified a unique fimbrial operon, peg, present in $S$. Gallinarum, $S$. Enteritidis and also $S$. Paratyphi. The peg operon displays $60-70 \%$ sequence conservation with the stc operon of $S$. Typhimurium and is located in the same relative position. The peg operon belongs to the $\gamma$ clade of fimbriae and is predicted to be assembled via the chaperone usher pathway [27].

The work herein examined the fimbrial gene conservation in the published genomes of other $S$. enterica serovars and also searched for traits associated with phase variation. Isogenic $S$. Enteritidis mutants with insertions in the major fimbrial subunit of each of the fimbrial operons were constructed using lambda Red recombinase-mediated linear recombination [28] followed by P22/int transduction. Mutant phenotypes were then evaluated and confirmed using an established chicken colonisation model. 


\section{Methods In silico analysis of fimbrial loci}

The complete genome sequences of $S$. enterica serovar Enteritidis strain P125109 [26], S. Gallinarum strain 287/ 91 [26], S. Typhimurium SL1344 and S. Typhimurium DT104 were produced by the Pathogen Sequencing Unit, Wellcome Trust Sanger Institute, UK http:// www.sanger.ac.uk/Projects/Salmonella/. Published genome sequences were obtained from the National Center for Biotechnology Information (NCBI) and are described with their RefSeq-curated accession numbers; $S$. Typhimurium LT2 NC_003197 [29], S. Typhi CT18 NC_003198 [30], S. Typhi Ty2 NC_004631 [31] and S. Choleraesuis SC-B67 NC_006905 [32]. Fimbrial gene sequences were identified from the primary literature and databases via NCBI Entrez and the genome sequences were visualised and compared using Artemis and Artemis Comparison Tool ACT $[33,34]$. Direct and indirect repeat sequences were searched for as described [35]. A Perl script was written to isolate and visualise $S$. Enteritidis fimbrial operons and is available from the authors on request.

\section{Bacterial strains and plasmids}

S. Enteritidis phage type 4 strain P125109 (NCTC 13349) was isolated from a poultry-associated outbreak in the UK and is naturally nalidixic acid resistant. A spontaneous nalidixic acid resistant derivative of $S$. Enteritidis S1400 [19] was selected by standard methods and it exhibits wild-type growth and chick colonisation phenotypes (data not shown). Strains were cultured in Luria-Bertani (LB) medium supplemented with antibiotics at the following concentrations where appropriate: nalidixic acid (Nal, $\left.20 \mu \mathrm{g} \mathrm{ml}^{-1}\right)$, novobiocin $\left(1 \mu \mathrm{g} \mathrm{ml}^{-1}\right)$, ampicillin (100 $\mu \mathrm{g} \mathrm{ml}-1)$ and chloramphenicol $(25 \mu \mathrm{g} \mathrm{ml}-1)$. Plasmids pCP20 [36], pKD3 and pKD46 [28] were obtained from the E. coli Genetic Stock Centre, Yale University. Plasmids pCR4Blunt-TOPO (Invitrogen, Paisley, UK) and pACYC177 [37] were used for cloning in E. coli K-12 strain TOP10F' (Invitrogen, Paisley, UK).

\section{Construction and validation of major fimbrial subunit mutations}

Primers were designed to amplify the pKD3-encoded chloramphenicol resistance cassette, including $40 \mathrm{bp}$ homology extensions from the 5 ' and 3 ' of each predicted major fimbrial subunit gene (Table 1). The extensions were designed such that the region between the start and stop codon of each major fimbrial subunit gene would be replaced by the chloramphenicol resistance cassette. PCR products were purified and electroporated into $S$. Enteritidis harbouring the helper plasmid pKD46, following induction of the Red recombinase with $10 \mathrm{mM}$ L-arabinose at $30^{\circ} \mathrm{C}$ as previously described [28]. Recombinants were selected on LB-agar containing chloramphenicol and cured of pKD46 by culture at $37^{\circ} \mathrm{C}$ in the absence of ampicillin. Mutations were confirmed at the expected position in the genome by PCR with primers specific to the chloramphenicol resistance cassette and primers flanking each major fimbrial subunit gene (Table 2). Mutations were also confirmed by Southern blotting with HindIIIdigested genomic DNA from wild-type and mutant strains using the cat gene as a probe. Attempts were made to transduce each mutation using bacteriophage P22/int into an archived strain to reduce the likelihood that phenotypes are the result of second site defects. For unknown reasons, three mutations could not be transduced, therefore the original recombinant was compared relative to the parent strain. Growth kinetics of all mutants were determined by diluting an overnight culture of $S$. Enteritidis wild-type or mutant strain 1:1000 in LB medium and measuring the absorbance at $600 \mathrm{~nm}$ every 30 minutes for 24 hours using a Bioscreen-C real-time spectrophotometer (Thermo ${ }^{\circledR}$, Helsinki, Finland).

\section{FLP recombinase-mediated excision of the chloramphenicol resistance cassette}

To remove the chloramphenicol resistance cassette from the $\Delta p e g A:: c a t$ mutant and create a predicted non-polar mutation, the temperature-sensitive plasmid pCP20 was introduced and expression of FLP recombinase induced by culture at $42^{\circ} \mathrm{C}$ in the absence of antibiotic selection as described [28]. FLP-mediated recombination between flippase recognition target (FRT) sites flanking the pKD3derived chloramphenicol resistance cassette was confirmed by PCR using primers flanking pegA. Excision of the chloramphenicol cassette was predicted to result in an 84 nucleotide in-frame scar between the pegA start and stop codons. The second codon in the scar is a stop codon, however pegA is not predicted to be translationally coupled to the 3' gene and therefore polar effects are not anticipated at the level of transcription or translation.

\section{Trans-complementation of the pegA::cat mutant}

The pegA coding sequence was amplified by PCR from $S$. Enteritidis P125109 genomic DNA using Pfu proof-reading DNA polymerase (Promega, Madison, USA) with primers pegA-for and pegA-rev containing ClaI restriction endonuclease cleavage sites. The $p e g A$ amplicon was ligated into pCR4Blunt-TOPO via topoisomerase I and transformed into chemically-competent E. coli TOP10 F' cells as described by the manufacturer (Invitrogen, Paisley, UK). A recombinant was verified by PCR with pegAspecific primers and digestion with ClaI. The ClaI fragment containing pegA was then sub-cloned into pACYC177 using T4 DNA ligase. Recombinant plasmids with the insert in the sense $\left(\mathrm{p} p e g A_{\mathrm{fwd}}\right)$ and antisense ( $\mathrm{p} p e$ $g A_{\text {rev }}$ ) orientation relative to the kanamycin resistance gene promoter of pACYC177 were isolated and electropo- 
Table I: Primers used to construct major fimbrial subunit mutations in S. Enteritidis PI25I09

\begin{tabular}{|c|c|}
\hline Name & Sequence (5'-3') \\
\hline stbAFmut & ATGTCTATGAAAAAATATTTAGCAATGATCACAGGCTCGCTGTGTAGGCTGGAGCTGCTTCG \\
\hline stbARmut & TTATTTATACGAAACGGCGTATTGTAGGGTGGCAGCGACTCATATGAATATCCTCCTTA \\
\hline pegAFmut & ATGAAACGTTCACTTATTGCTGCTTCTGTATTGTCTGCTGTGTGTAGGCTGGAGCTGCTTCG \\
\hline pegARmut & TTAATCAGTTAATACCGTCATCGTCAGTACAGATTCAACACATATGAATATCCTCCTTA \\
\hline stdAFmut & GTGCTTCGTTTAACACCAGGCGTTTATTATTCATACGAATTGTGTAGGCTGGAGCTGCTTCG \\
\hline stdARmut & TCACAGGTATTTCAGGGTGTAGGTGACGGATGCGTTGAAGCATATGAATATCCTCCTTA \\
\hline steAFmut & ATGAAGTCATCTCATTTTTGTAAACTGGCAGTAACTGCATGTGTAGGCTGGAGCTGCTTCG \\
\hline steARmut & TTACAGGTAAGAGATAGTGACGTTGGCGGCGCTGCTGAACATATGAATATCCTCCTTA \\
\hline stfAFmut & ATGAATACAGCAGTAAAAGCTGCGGTTGCTGCCGCACTGGTGTGTAGGCTGGAGCTGCTTCG \\
\hline stfARmut & TTACAGATAGCTGATCGTGAAGTTTACGGTGCTGCTGAATCATATGAATATCCTCCTTA \\
\hline sthAFmut & ATGTTTAATAAGAAAATTATCATCCTGGCAATGTTAACTTGTGTAGGCTGGAGCTGCTTCG \\
\hline sthARmut & TTACTGATACGAAACGGTATACGTAACCTGAGTGCTAACACATATGAATATCCTCCTTA \\
\hline stiAfmut & ATGAAACTCTCCTTAAAAACACTCACTGTGGCACTGCCGTGTGTAGGCTGGAGCTGCTTCG \\
\hline stiARmut & TCAGTTATATTGCAGATAGAATGTTGCGGTTGCATCGACCCATATGAATATCCTCCTTA \\
\hline bcfAFmut & ATGAAAAAGCCTGTACTAGCATTAATGGTCTCTGCCATTGTGTGTAGGCTGGAGCTGCTTC \\
\hline bcfARmut & TCAGGAATAAACCATGCTAAATGTCGCCGTCGCGGTAACCATATGAATATCCTCCTTA \\
\hline csgAFmut & ATGAAACTTTTAAAAGTGGCAGCATTCGCAGCAATCGTAGTTGTGTAGGCTGGAGCTGCTTCG \\
\hline csgARmut & TTAATACTGGTTAGCCGTGGCGTTGTTGCCAAAACCAACCCATATGAATATCCTCCTTA \\
\hline IpfAFmut & ATGGAGTTTTTAATGAAAAAGGTTGTTTTTGCTCTGTCTGTGTGTAGGCTGGAGCTGCTTCG \\
\hline IpfARmut & TTATTCGTAGGACAGGTTGAAGTCACTTCTGCGTTACCGCATATGAATATCCTCCTTA \\
\hline fimAFmut & ACCTCTACTATTGCGAGTCTGATGTTTGTCGCTGGCGCATGTGTAGGCTGGAGCTGCTTCG \\
\hline fimARmut & TTATTCGTATTTCATGATAAAGGTGGCGTCGGCATTAGCCTGCATATGAATATCCTCCTTA \\
\hline sefAFmut & ATGCGTAAATCAGCATCTGCAGTAGCAGTTCTTGCTTTAATGTGTAGGCTGGAGCTGCTTCG \\
\hline sefARmut & GTTTTGATACTGCTGAACGTAGAAGGTCGCAGTGGGTCCATTTCATATGAATATCCTCCTTA \\
\hline safAFmut & GTGGTTATTCAAATGAAAAGCATAAAAAAATTGATTATCGTGTGTAGGCTGGAGCTGCTTCG \\
\hline safARmut & ITAAGGCTGATATCCCACTACGTCTACAGTTATTGGGTACCATATGAATATCCTCCTTA \\
\hline
\end{tabular}

The primers were designed to mutate the major fimbrial subunit by lambda Red recombinase-mediated integration of linear PCR products. Forward and reverse primers were used to amplify the PKD3-derived chloramphenicol cassette and contain 40 bp homology extensions 5' and 3' of the target gene. 
Table 2: Primer combinations used to validate each fimbrial mutation.

\begin{tabular}{|c|c|c|}
\hline Primer combination & Predicted amplicon size (bp) & Sequence (5'-3') \\
\hline bcfAFOR + Cl & 633 & TGCACTATCCGCAACGATATATTT \\
\hline bcfAREV + C2 & 507 & TAAAATACGCTTTCGCGATCGGTCGGT \\
\hline $\operatorname{csgAFOR}+\mathrm{C2}$ & 173 & CAAGGAGCAATAAAGTATGCATAATTT \\
\hline csgAREV + Cl & 302 & CAGCAGTTGTAGTGCAGAAACAGTCGCATA \\
\hline IpfAFOR + C2 & 867 & TTAGTTACGCGCTGTGTCAA \\
\hline IPfAREV + CI & 288 & ATCCAATACCCACCTCTATACACTCCA \\
\hline fimAFOR +Cl & 807 & AACCTCAGATCGCACCTGCTGC \\
\hline fimAREV + C2 & 429 & ATGCCGACATGACGCCAGACC \\
\hline sefAFOR + Cl & 373 & CTATTAATGGGGATGTTGTGTAA \\
\hline sefAREV + C2 & 946 & СТАATAАТСТСТTAТААТTTC \\
\hline safAFOR + Cl & 701 & TGAGACTCTCTCATTGGAGCGCT \\
\hline SafAREV + C2 & 597 & AATTGAGGTCAAGGGTCGCGCC \\
\hline stbAFOR + C2 & 887 & TTAATGGTGGGGGACATCGTA \\
\hline stbAREV + Cl & 295 & TTATTTTTACCACTCCATAAGCACGAA \\
\hline pegAFOR + C2 & 179 & CACAAGCCAGGCATAATGCAATCATC \\
\hline pegAREV + Cl & 377 & ACATTGCGATAACTTCCTGTCTATGAGAA \\
\hline stdAFOR + C2 & 587 & GCTGTACCGTACCTGACTGTC \\
\hline stdAREV + Cl & 714 & TGTTTTTAAATTTCATCCGCGAAG \\
\hline steAFOR + Cl & 739 & TACGACAACGCCTATATAATA \\
\hline steAREV + C2 & 600 & AGCAGCGTGGAGTGTCCCAGGTCAGC \\
\hline stfAFOR + Cl & 283 & CATATAAACATGGGGTATTGATGA \\
\hline stfAREV + C2 & 155 & GGCTGGCATCATCTTTAACA \\
\hline sthAFOR + Cl & 584 & GCGTTGATTTTGTTAATGC \\
\hline sthAREV + C2 & 704 & GAAAGCTCACGATTTGAGATCAAC \\
\hline stiAFOR + C2 & 385 & TTTGGCCGACAACACACTATG \\
\hline stiAREV + Cl & 661 & GTAAATCAGCTTAAATTCCG \\
\hline $\mathrm{Cl}$ & - & TTATACGCAAGGCGACAAGG \\
\hline $\mathrm{C} 2$ & - & GATCTTCCGTCACAGGTAGG \\
\hline
\end{tabular}


rated into $S$. Enteritidis P125109 $\triangle p e g A:: c a t$ with selection for ampicillin resistance.

\section{Experimental animals}

Inoculation of chickens with $S$. Enteritidis wild-type, mutant and trans-complemented strains was conducted according to the requirements of the Animal (Scientific Procedures) Act 1986 (PPL 30/1998) with the approval of the local Ethical Review Committee. Specific pathogenfree out-bred Rhode Island Red chickens were reared at the Institute for Animal Health and housed in group cages in bio-secure accommodation. Birds were fed a vegetablebased diet (Special Diet Services, Manea, Cambridgeshire, UK) with access to water ad libitum. To reduce inter-animal variation, chickens were orally dosed on the day of hatch with $0.1 \mathrm{ml}$ Salmonella-free adult gut flora cultured as described [38]. Owing to constraints of space, the phenotype of each fimbrial mutant could not be simultaneously evaluated relative to the parent. Rather, 4 groups of 15 birds were accommodated per room with 3 groups each receiving a different fimbrial mutant strain and one group the corresponding parent strain. Approximately 1.5 $\times 10^{8}$ colony-forming units (CFU) of stationary phase LBgrown Salmonella were given by oral gavage at 18-daysold. Inocula were confirmed to be comparable by retrospective plating of serial dilutions to selective media. Five birds from each group were sacrificed by cervical dislocation at 3, 7 and 10 days post-inoculation and the liver, spleen, caecal contents, caecal wall, ileal contents and ileal wall were recovered aseptically and diluted 1:10 in phosphate-buffered saline for homogenisation. A rotary blade was used to homogenise the samples and serial ten-fold dilutions were plated on brilliant green agar containing novobiocin and nalidixic acid. As each sample was diluted 1:10 for homogenisation and $20 \mu \mathrm{l}$ of this was plated in triplicate, the theoretical limit of detection by direct plating is $\log _{10} 2.2 \mathrm{CFU} / \mathrm{g}$. For some samples bacterial counts were below the limit of detection by direct plating and therefore enrichment was used. The homogenized sample was incubated overnight at $37^{\circ} \mathrm{C}$ in a final concentration of $1 \times$ selenite broth before being plated on brilliant green agar plates supplemented with nalidixic acid and novobiocin. This results in a qualitative rather than a quantitative count but was given an arbitrary figure of $\log _{10} 1 \mathrm{CFU} /$ $\mathrm{g}$ as the sample diluted $10^{-1}$ must have contained at least one viable organism. Owing to the difficulty separating caecal contents from the mucosa, the total caecal load is presented as a measure of colonisation of this site. This represents the mean viable count of $S$. Enteritidis in caecal content and mucosa samples, including biological and technical replicates.

To confirm the role of pegA in intestinal colonisation of chickens by $S$. Enteritidis, P125109 wild-type, $\Delta p e g A:: c a t$ mutant, $\Delta p e g A$ mutant, $\Delta p e g A:: c a t \quad\left[p p e g A_{f w d}\right]$ and $\triangle p e g A:: c a t\left[p p e g A_{\text {rev }}\right]$ were given by oral gavage to ten 18 day-old Rhode Island Red chickens as above. Post mortem examinations were performed at 1 and 3 days post-inoculation ( $n=5$ per time interval) and bacteria at enteric and systemic sites enumerated. Plasmid stability in the absence of antibiotic selection in vivo was evaluated by plating selected samples to media containing nalidixic acid with or without ampicillin.

\section{Statistical analysis}

Counts of viable bacteria were $\log _{10}$ transformed and a generalised linear model was constructed using the least square means \pm standard error of the mean (Statistical Analysis System version 9, SAS Institute, Cary, NC, USA). The significance of differences between test and control groups was determined by an F-test with data taken as repeated measurements. $P$ values $<0.05$ were considered significant.

\section{Results}

In silico analysis of S. Enteritidis PI25 109 fimbrial loci

Fourteen predicted fimbrial loci of the sequenced $S$. Enteritidis phage type 4 strain were identified [26]. Thirteen fimbrial loci are predicted to be encoded on the genome, whereas the P125109 pef operon is plasmid-encoded and highly similar to that of $S$. Typhimurium LT2 and $S$. Choleraesuis SC-B67. As S. Enteritidis pef was previously reported to play no significant role in colonisation of 1 and 5-day-old chicks [19], we elected to focus this study on chromosomally-encoded loci. Additional file 1 shows the predicted organisation of each fimbrial operon of strain P125109, together with \%G+C content of the locus and the location and e-values of Pfam subunit, usher and chaperone domains.

The analysis of the Pfam domains failed to identify a major fimbrial subunit in $\operatorname{csg}$ and saf, consistent with the prediction that they give rise to atypical fimbriae. The csg operon is not predicted to encode proteins with usher or chaperone domains, consistent with assembly of Csg fimbriae via a nucleator-dependent pathway [39]. The saf operon consists of a chaperone and usher domain. The adhesive component is formed by the main structural subunit whose sequence has been shown here to be highly variable and it is not located at the tip as with other chaperone/usher assembled fimbriae [40]. The saf fimbriae are composed of flexible linear multi-subunit fibers connected by short fibers or linkers which allow flexibility in the final structure [40].

The conservation and organisation of fimbrial loci in the genomes of sequenced strains of $S$. enterica was analysed using the Artemis Comparison Tool. This revealed differences in the number and location of fimbrial loci between the strains as well as the presence of predicted truncations 
and pseudogenes (Figure 1). At the nucleotide level, 56 of 71 fimbrial genes examined possessed $\geq 95 \%$ identity (Additional file 2). These include all of the genes of the fimbrial operons $s t i, s t b$, fim, csg and $l p f$, implying that their function may be conserved.

S. Enteritidis P125109 shares 10 of its 13 fimbriae with the sequenced $S$. Typhimurium strains. The $S$. Enteritidis ste, sef and peg operons are absent from the sequenced serovar Typhimurium strains, whereas the latter posses stc and stj operons that we do not find in P125109 (Figure 1).

We previously reported that the percentage of fimbrial genes that are pseudogenes in $S$. Gallinarum is greater than the genomic mean [26]. In addition we found here that the host-specific strains $S$. Typhi CT18 and S. Typhi Ty2 (data not shown) possessed the highest number of predicted fimbrial pseudogenes (based on the presence of at least one stop codon in the predicted coding sequence). The percentage of fimbrial genes that are pseudogenes in $S$. Typhi CT18 and S. Typhi Ty2 is $14 \%$ and $16 \%$ respectively, whereas the genomic mean of pseudogenes is $4.4 \%$. In contrast the broad host-range serovars Enteritidis and Typhimurium LT2, DT104 and SL1344 appeared to contain an intact repertoire of fimbriae (data not shown) and the host-restricted serovar Choleraesuis maintained an intermediate number of predicted functional fimbrial genes. No single fimbrial locus could be correlated with host-specificity; however as has previously been suggested it is plausible that the loss of fimbrial genes in host-specific and -restricted serovars is associated with the narrowing of the niches they may occupy $[26,29,30]$.

Fimbrial genes in some bacteria are subject to phase variable (on-off) expression that may be mediated via recombination (e.g. FimBE-mediated inversion of the fimA promoter in E. coli [41]), epigenetic regulation dependent on Dam methylation (e.g. control of Pap pili in uropathogenic E. coli [42]) or slipped-strand mis-pairing between homo- or hetero-polymeric tracts (e.g. assembly and maturation of Neisserial pilin reviewed in [43]). In Salmonella, evidence exists for phase variable expression of Type I fimbriae [44-46] and long-polar fimbriae [47]. Further, epigenetic regulation of the pef genes in $S$. Typhimurium by Dam methylation has been described [48] and expression of std fimbrial genes has been observed to be repressed in a $S$. Typhimurium Dam methylase mutant $[49,50]$.

We searched $S$. Enteritidis fimbrial loci for traits associated with phase variation. Genes with homology to known recombinases were not detected within or proximal to fimbrial loci. Putative transposase and integrase genes associated with DNA mobility were observed proximal to the saf, sef and fim operons. Direct or inverted repeat sequences that may serve as substrates for recombination were not detected. A pattern-matching search was carried out for the Dam methylase target sequence GATC within and proximal to P125109 fimbrial operons. This identified hundreds of potential targets (Additional file 3 ), including those predicted to be methylated in the $S$. Typhimurium pef cluster [48]. Where S. Typhimurium strains SL1344 and LT2 possess GATC sites at $-98,-110$ and -212 relative to the start of $p e f B, S$. Enteritidis P125109 possessed only the sites at -110 and -212 , but an additional site at +47 in $p e f B$ that is absent in the two Typhimurium strains (Additional file 3a, grey shaded area). Three potential Dam methylation target sites were also identified upstream of the std operon $(-88,-97$ and $110)$ in S. Enteritidis P125109. This density of GATC sites is higher than random distribution would predict and correlates with the Dam-dependent repression of the std genes as detected by microarray analysis [49] and using antibody against StdA [50] (Additional file 3a, purple shaded area). Predicted Dam methylase targets were also identified upstream of the sef, sti and stf operons in S. Enteritidis P125109 (Additional file 3). Hundreds of homopolymeric tracts comprising 4 or more A or $\mathrm{C}$ residues were identified within fimbrial loci. Several conserved hetero-polymeric tracts were identified using a variable tandem repeat pattern finder, however only one was present in a fimbrial gene (ten repeated 6-mers (GACCAT) within stdA).

\section{Construction of S. Enteritidis major fimbrial subunit mutants}

Amplicons for the 13 chromosomally-encoded predicted major fimbrial subunit genes of $S$. Enteritidis P125109, were produced in order to delete each one via lambda Red recombinase-mediated linear recombination. Despite repeated attempts, pKD46 failed to mediate homologous recombination of linear amplicons in $S$. Enteritidis P125109 under conditions suitable for other S. enterica strains. However all 13 genes were successfully disrupted in the $S$. Enteritidis phage type 4 strain S1400nal ${ }^{\mathrm{R}}$, which is known to efficiently colonise the avian intestines $[19,20]$. Ten of the major fimbrial subunit gene deletions (marked by insertion of a chloramphenicol resistance cassette between the predicted start and stop codons) were successfully transduced into $S$. Enteritidis P125109 using bacteriophage P22/int. Transductants of $S$. Enteritidis $\mathrm{P} 125109$ or the archived S1400nal ${ }^{R}$ strain were not isolated for three of the mutated fimbrial constructs ( $\triangle$ safA::cat, $\Delta$ fimA::cat and $\Delta$ steA::cat). All of the successfully recovered isogenic mutants were verified by PCR and no growth defects were detected in batch culture (data not shown).

\section{Screening of S. Enteritidis fimbrial subunit mutants in a chick colonisation model}

Although P125109 is known to colonise the intestines of streptomycin pre-treated mice [51], no data existed on the colonisation dynamics of the sequenced $S$. Enteritidis 


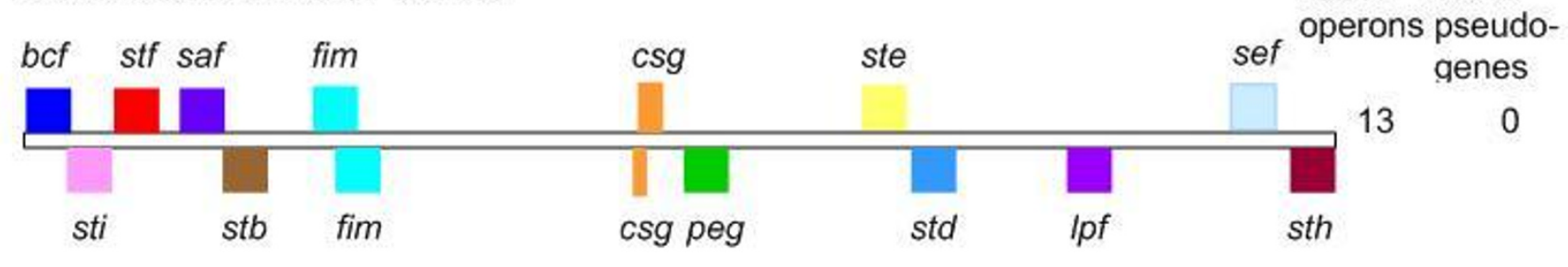

\section{Salmonella Typhimurium LT2}

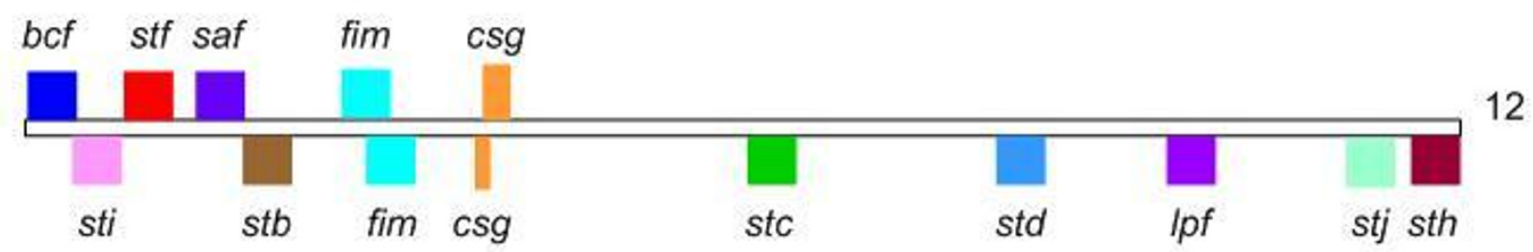

0

\section{Salmonella Choleraesuis SC-B67}

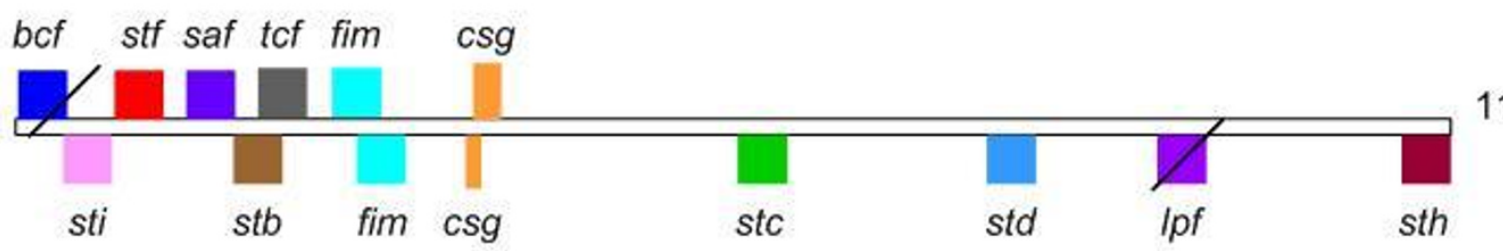

\section{Salmonella Typhi CT18}

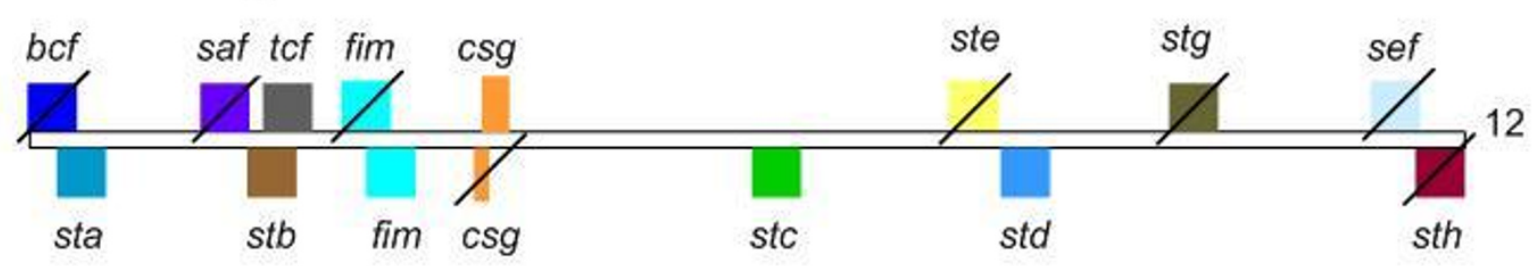

\section{Salmonella Gallinarum 287/91}

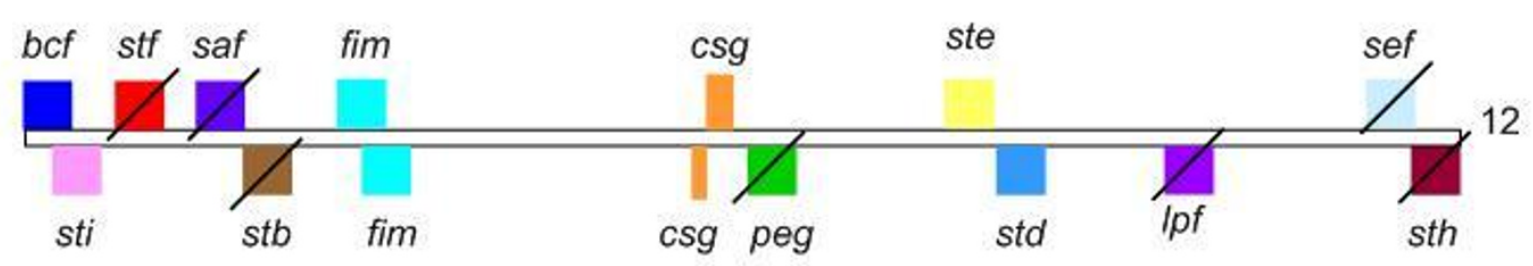

\section{Figure I}

Schematic representation of the repertoire and relative genomic location of fimbrial loci in the published genomes of $S$. enterica serovars. Each coloured box represents a distinct fimbrial locus encoded in the sense (top) or antisense (bottom) orientation. Boxes of the same colour on both strands represent divergently transcribed operons. A diagonal line through the box indicates that at least one gene in the operon is a predicted pseudogene. The repertoire of $S$. Typhimurium and S. Typhi is representative of other sequenced strains of the same serovar. All genomes are aligned relative to their predicted origin. Not to scale. 
strain P125109 in chickens. A pilot experiment was therefore performed to evaluate the magnitude and duration of colonisation of enteric and systemic sites at intervals postoral inoculation and to gain an assessment of inter-animal variation. Following oral gavage of 18 -day-old outbred specific pathogen-free Rhode Island Red chickens birds with $1.5 \times 10^{8} \mathrm{CFU}$, the caecal contents and mucosa were colonised by $4-5 \log _{10}$ CFU/g of strain P125109 at days 1,3 and 7 post-infection ( $n=5$ per time interval; Additional file 4). Bacterial colonisation of the ileum and translocation to the liver and spleen was detected, with recoveries at around the limit of detection at $2-3 \log _{10}$ CFU/g by days 3 and 7 (Additional file 4).

Each fimbrial mutant was separately inoculated into groups of 15 Rhode Island Red chickens at 18 days-of-age and bacteria enumerated at enteric and systemic sites at 3 , 7 and 10 days-post inoculation relative to the corresponding parent strain. As the caeca are a key site of bacterial persistence in the avian gut [52,53], (Additional file 4) and attenuation of defined and random Salmonella mutants is reliably detected at this site [12], the total caecal load is presented here as a measure of intestinal colonisation, representing the mean of the caecal wall and mucosa bacterial counts. We cannot preclude the possibility that some fimbriae mediate a specific tissue tropism that was not detected herein. Recoveries of viable bacteria from the liver and spleen were often close to the limit of detection by direct plating in chickens infected with wildtype strains (Additional file 4) and mutant strains (data not shown). Where adequate bacteria were recovered to permit a statistical analysis, no significant differences were observed at these sites. Figure 2 shows the caecal colonisation kinetics of $s t b$,peg, std, stf, sth, sti, bcf, csg, lpf and sef major fimbrial subunit mutants of $S$. Enteritidis P125109 relative to the parent strain. The caecal loads of fim, saf and ste major fimbrial subunit mutants of $S$. Enteritidis strain S1400nal ${ }^{R}$ relative to the parent are shown in Figure 3.

The S. Enteritidis P125109 $\Delta s t b A::$ cat fimbrial mutant was recovered from the chicken caeca at lower levels than the wild-type at all intervals post-inoculation (Figure 2A), with differences becoming significant by days 7 and $10(P$ $=0.0081$ and $P=0.03$, respectively). This is consistent with the attenuation of a $S$. Typhimurium $s t b C$ mutant in chick caeca detected by signature-tagged mutagenesis [12]. The $\Delta$ pegA::cat mutant of S. Enteritidis P125109 was significantly impaired in colonisation of the caeca at days 3 and 7 post-inoculation compared with the wild-type ( $P$ $=0.0006$ and $P=0.0002$ respectively), although recoveries by day 10 were comparable (Figure 2B). The P125109 $\triangle b c f A:: c a t$ mutant, was recovered in significantly lower numbers than the parent strain at day $7(P=0.04)$, but not at other times (Figure $2 \mathrm{G}$ ) and the S1400nal ${ }^{\mathrm{R}} \Delta$ steA::cat mutant was recovered in significantly lower numbers than the parent but only at day $10(P=0.0034$; Figure $3 \mathrm{C})$. No other fimbrial mutations significantly influenced the course of caecal colonisation at the $95 \%$ confidence interval.

\section{Confirmation of the role of PegA in colonisation of chickens by S. Enteritidis}

Figure 2B implies a role for PegA in the colonisation of the chicken caeca. However, the $\Delta p e g A:: c a t$ mutation was transduced from S1400nal ${ }^{R}$ into P125109 prior to analysis in chickens and a theoretical possibility exists that other traits proximal to the pegA gene were transferred that resulted in attenuation. To address this, we analysed the phenotype of the original S1400nal ${ }^{\mathrm{R}} \Delta p e g A:$ :cat mutant relative to the parent and sought to restore the mutant to the wild-type level of colonisation by plasmid-mediated trans-complementation using the same experimental design as above. As with the $\triangle p e g A:: c a t$ mutant of P125109 (Figure 2B) an approximate $2 \log _{10} \mathrm{CFU} / \mathrm{g}$ reduction in the total caecal load of the S1400nalR $\Delta p e g A:: c a t$ mutant was detected at days 3 and 7 post-inoculation relative to the parent strain (Figure 4; $P=0.0135$ and $P=0.0088$, respectively). However, as with the $\triangle p e g A::$ cat mutant of strain P125109, no significant difference was detected by day 10 post-inoculation.

The chloramphenicol resistance cassette was excised from the P125109 $\Delta$ pegA::cat fimbrial mutant to determine if polar effects on the expression of 3 ' genes may explain the attenuation observed. This addresses the possibility that pegA may not be involved in colonisation per se, but that downstream genes participate in the expression of surface structure(s) that may include distally-encoded fimbrial subunits. Excision was achieved by transient expression of flippase recombinase as described in the Methods. The total caecal loads of both the S. Enteritidis P125109 $\triangle p e g A::$ cat and $\triangle p e g A$ mutant were approximately two orders of magnitude lower than the parent strain at 1 and 3 days post-oral inoculation of chickens (Figure 5). No significant difference existed between the caecal loads of the $\triangle p e g A:: c a t$ and $\triangle p e g A$ mutants $(P$ values 0.27 and 0.64 at 1 and 3 days post-inoculation, respectively); however in both cases a highly significant reduction in caecal load was detected for each mutant relative to the parent strain ( $P$ values $<0.0001$ at 1 day post-infection), consistent with previous findings.

A pACYC177-derived plasmid was created in which the $S$. Enteritidis P125109 pegA gene was cloned in the same orientation as the kanamycin promoter ( $\left.p p e g A_{\mathrm{fwd}}\right)$, or in the antisense orientation $\left(\mathrm{p} p e g A_{\text {rev }}\right)$. This replicon was selected for trans-complementation as it did not impair the virulence of $S$. Typhimurium in mouse co-infection studies [54]. Introduction of $p p e g A_{\text {rev }}$ into the $S$. Enteri- 

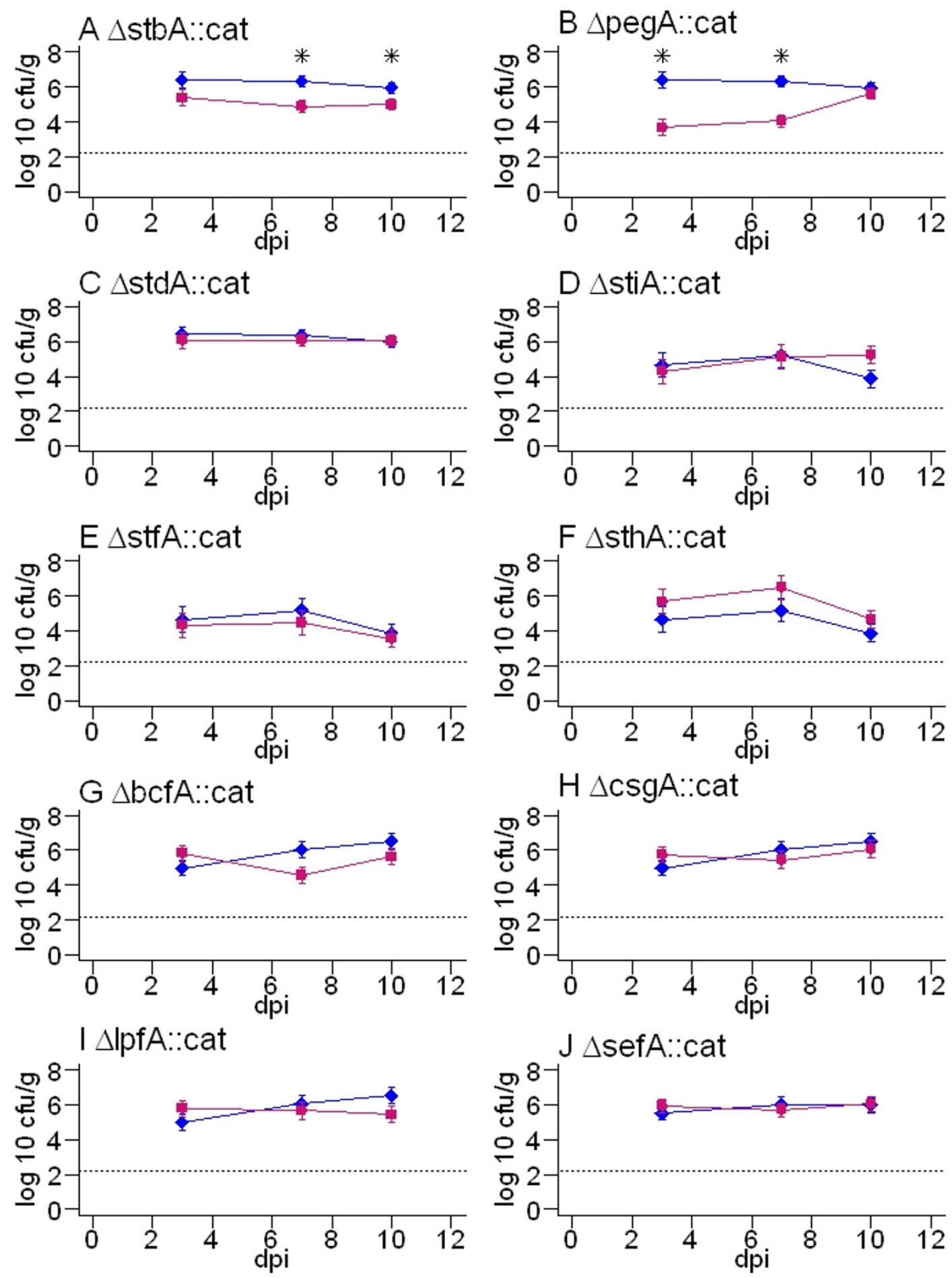

Figure 2

Total caecal load of S. Enteritidis PI 25 I 09 wild-type and major fimbrial subunit mutant strains at 3, 7 and I0 days post-oral inoculation of I 8-day-old out-bred Rhode Island Red chickens. Blue lines with diamonds denote the wild-type strain and pink lines with squares denote the fimbrial mutants. The dashed line indicates the theoretical limit of detection by direct plating $\left(2.2 \log _{10}\right.$ CFU/g). The data reflect the mean \pm standard error of the mean from five birds at each time interval. F-tests of the difference in recovery of wild-type and mutant strains at each time interval were performed and $P$ values $<0.05$ are marked with an asterisk. 

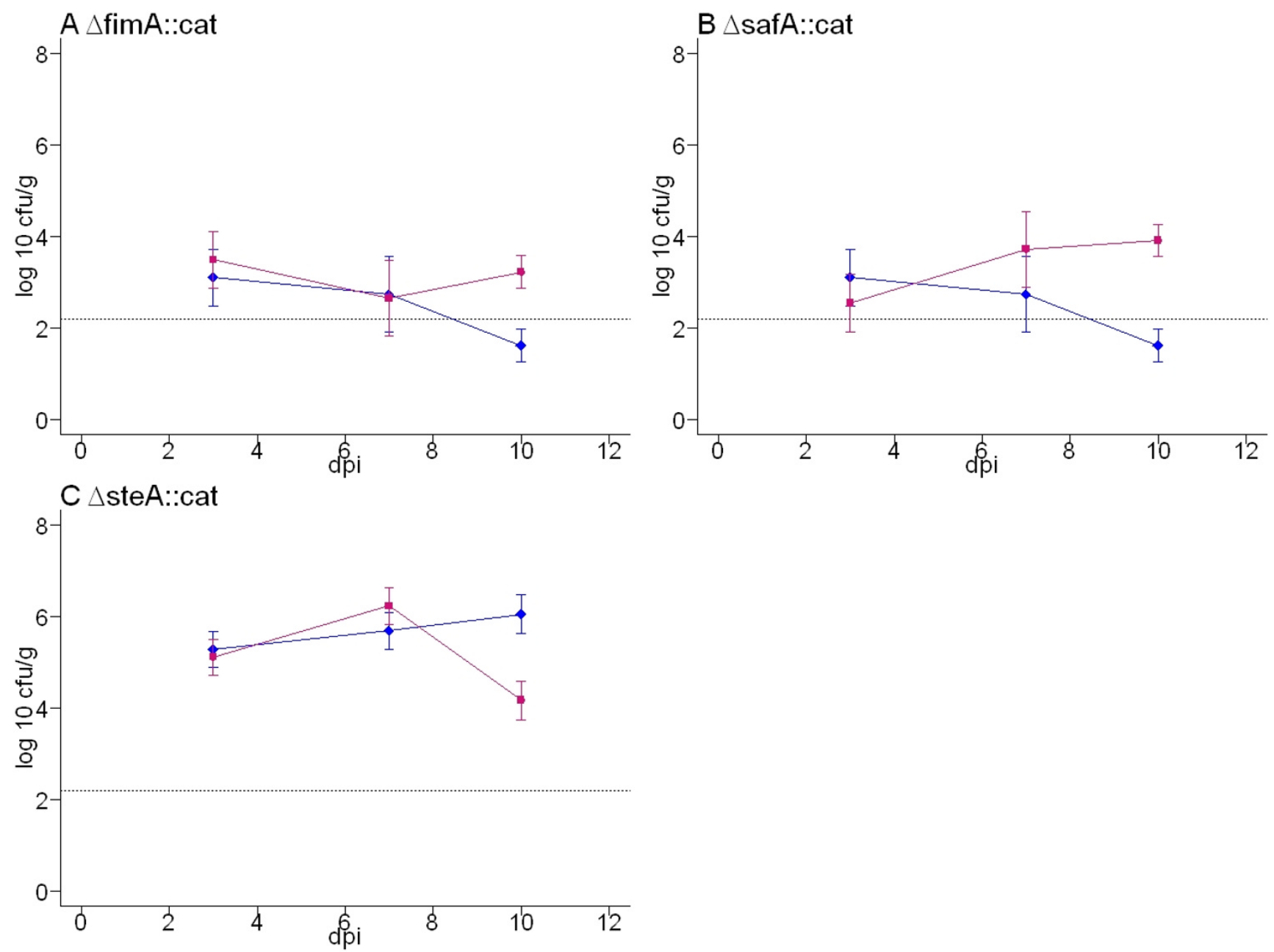

Figure 3

Total caecal load of S. Enteritidis S I400nalR wild-type, $\Delta$ fimA::cat, $\Delta$ steA::cat and $\Delta$ safA::cat mutant strains at 3, 7 and 10 days post-oral inoculation of I 8-day-old out-bred Rhode Island Red chickens. Blue lines with diamonds denote the wild-type strain and pink lines with squares denote the fimbrial mutants. The dashed line indicates the theoretical limit of detection by direct plating $\left(2.2 \log _{10}\right.$ CFU/g). Samples positive only by enrichment culture were given an arbitrary value of I $\log _{10} \mathrm{CFU} / \mathrm{g}$ since at least one viable organism must have been present. The data reflect the mean \pm standard error of the mean from five birds at each time interval. F-tests of the difference in recovery of wild-type and mutant strains at each time interval were performed and $P$ values $<0.05$ are marked with an asterisk.

tidis P125109 $\triangle p e g A$ mutant resulted in total caecal counts that were not significantly different to the $\Delta p e g A$ fimbrial mutant at both 1 and 3 days post-oral inoculation of chickens ( $P=0.24$ and $P=0.07$, respectively). However, recoveries of the ppeg $A_{\text {rev }}$-bearing strain were lower than for the $\Delta p e g A:: c a t$ mutant alone at both time points, indicating that plasmid carriage may exert a slight fitness cost. The $\triangle p e g A$ mutant harbouring $p p e g A_{\text {rev }}$ was significantly attenuated compared to the parent strain at 1 and 3 days post-inoculation $(P$ values $<0.0001)$. In contrast, introduction of the pACYC177-derived plasmid containing $p e g A$ in the sense orientation into the $\Delta p e g A$ mutant partially restored the ability of the mutant strain to colonise the caeca at both time points relative to the wild-type strain $(P=0.0005$ and $P=0.02$ at 1 and 3 days post-inoculation, respectively) and to the $\Delta p e g A$ fimbrial mutant $(P=0.0014$ and $P=0.0005$ at 1 and 3 days postinoculation, respectively). Plating of tissue homogenates to media with or without ampicillin indicated that the plasmid was stably maintained in the absence of antibiotic selection in vivo. Taken together these data confirm that pegA plays a role in caecal colonisation of the avian intestines by $S$. Enteritidis.

\section{Discussion}

$S$. Enteritidis phage type 4 is an important zoonotic pathogen and the factors mediating persistence in the avian reservoir are ill-defined. Toward an understanding of the 


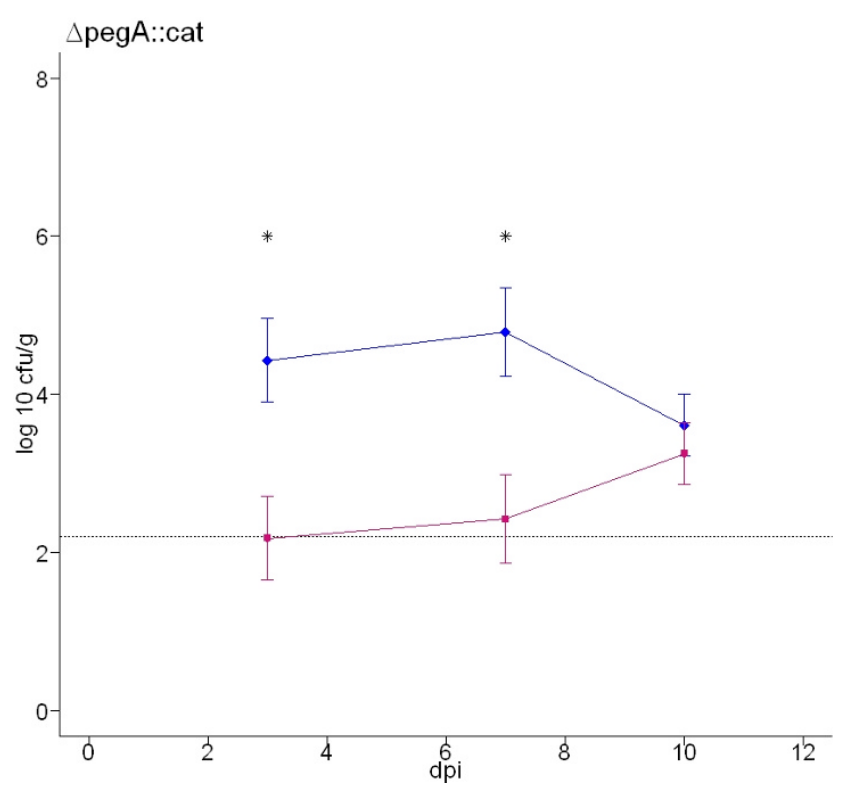

Figure 4

Total caecal load of S. Enteritidis S I 400nalR wild-type and $\Delta$ pegA::cat fimbrial mutant strains at 3, 7 and $I 0$ days post-oral inoculation of I 8-day-old out-bred Rhode Island Red chickens. Blue lines with diamonds denote the wild-type strain and pink lines with squares denote the fimbrial mutant. The dashed line indicates the theoretical limit of detection by direct plating $\left(2.2 \log _{10} \mathrm{CFU} /\right.$ $\mathrm{g})$. The data reflect the mean \pm standard error of the mean from five birds at each time interval. F-tests of the difference in recovery of wild-type and mutant strains at each time interval were performed and $P$ values $<0.05$ are marked with an asterisk.

molecular mechanisms by which $S$. Enteritidis colonises the chicken gut, the role of fimbriae was examined as these influence the carriage, virulence and tropism of other members of the Enterobacteriaceae. From the raw genome sequence of $S$. Enteritidis P125109, 13 intact chromosomal fimbrial loci were predicted. By comparing the sequence and distribution of the fimbrial loci with the published genomes of other $S$. enterica serovars in silico, no single locus correlated with host specificity. Microarray studies have indicated that a remarkable degree of conservation of fimbrial gene content exists among $26 \mathrm{~S}$. Enteritidis isolates from varied geographical locations, hosts and years [55] and between strains of other broad host range serovars $[56,57]$. However, sequencing of such loci is required to determine if subtle differences in gene function exist.

Systematic mutagenesis of each major fimbrial subunit gene and screening in a chicken model revealed that the majority of major fimbrial subunits played no significant role in colonisation of the caeca $(P$ values greater than 0.05). The absence of roles for $S$. Enteritidis Fim, Csg, Lpf and Sef fimbriae confirms previous reports that mutants lacking these fimbriae singly or in combination exhibit no significant defect in colonisation of chicks $[19,20,22]$. Conversely, the present study supports a role for Stb fimbriae in colonisation of the avian intestines by Salmonella that was suggested by the isolation of an $S$. Typhimurium $s t b C$ mutant by screening a library of signature-tagged mutants for attenuation in chicks [12]. The same screen of random mutants also identified attenuating mutations in $\operatorname{sth} B$ and $\operatorname{csg} D$, however roles for $\operatorname{sth} A$ and $\operatorname{csg} A$ were not observed herein and studies with defined non-polar mutants and trans-complemented strains will be required to establish if the sth and csg loci play a conserved or serovar-specific role in colonisation of chickens. Owing to the relatively short-term nature of the studies reported here, we cannot preclude the possibility that the fimbrial subunits examined may play a role in longer-term persistence in the avian intestines or indeed tropism for the reproductive tract and egg, and further studies will be required to investigate this.

For the first time, we have shown that $S$. Enteritidis P125109 and S1400nal ${ }^{R}$ mutants of the novel Peg fimbrial operon show statistically significant attenuation in chickens that can be partially restored by plasmid mediated trans-complementation. A mutant in which the polar effects of the deletion of pegA are not predicted at the transcriptional or translational level was also attenuated; further implying that the phenotype of pegA insertion mutants is not due to altered expression of downstream genes. The inability of the $p p e g A_{\text {fwd }}$ plasmid to fully restore colonisation to wild-type levels may reflect differences in the expression level of the fimbrial subunit in vivo and/or the fitness cost of maintaining the plasmid since recoveries of the $\triangle p e g A::$ cat mutant bearing pegA on pACYC177 in the antisense orientation were slightly lower than for the mutant alone.

Assays with cultured cells did not indicate any significant role for pegA in adherence to primary chick kidney cells, HD11 avian macrophage-like cells or HEp-2 human laryngeal epithelial cells (data not shown) and there was no correlation between in vitro and in vivo results, regardless of the fimbriae examined. However, this is not unexpected as many fimbriae are known to be poorly expressed during culture in laboratory media [58], but are induced in bovine and murine intestinal lumen $[58,59]$ and serve as antigens in mice [59].

Although there is attenuation of the $S$. Enteritidis pegA mutant, the peg $\mathrm{C}$ gene encoding a putative chaperone is a pseudogene in the sequenced strain of the poultryadapted serovar $S$. Gallinarum, which implies that the possession of the entire fimbrial operon is unlikely to be a prerequisite for chicken colonisation. It should be noted that the tissue distribution of $S$. Enteritidis and $S$. Galli- 


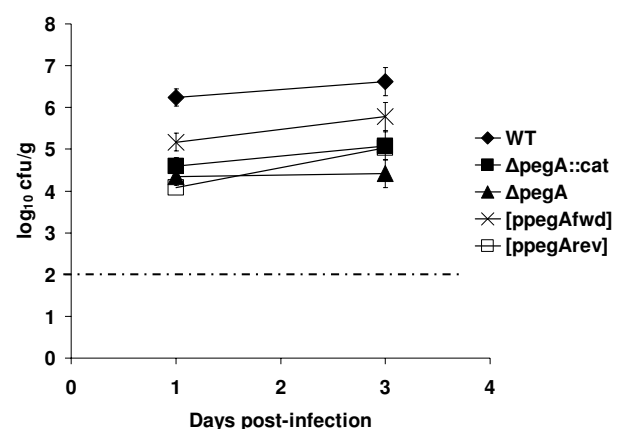

\section{Figure 5}

Plasmid-mediated trans-complementation of the $\triangle$ pegA::cat mutant of S. Enteritidis PI $25 \mathrm{I} 09$ at I and 3 days post-oral inoculation of I 8-day-old out-bred Rhode Island Red chickens. Total caecal load of the wildtype and mutant strain were compared to those of the PI25I09 $\triangle$ pegA::cat insertion mutant and $\triangle$ pegA strains in which pegA was introduced on plasmid pACYCI77 in either the forward or reverse orientation relative to the promoter of the kanamycin resistance gene. The data represent the mean total caecal load \pm standard error of the mean from five birds at each time interval for each strain. The dashed line indicates the theoretical limit of detection by direct plating $\left(2.2 \log _{10} \mathrm{CFU} / \mathrm{g}\right)$. F-tests of the difference in recovery of wild-type and mutant strains at each time interval were performed and $P$ values $<0.05$ are marked with an asterisk.

narum is markedly different in age-matched healthy outbred birds, with $S$. Gallinarum causing severe systemic disease with little enteric involvement whereas $S$. Enteritidis colonises the gut to a high level [7].

The absence of significant roles for $S$. Enteritidis fimbrial loci in isolation may reflect redundancy or the existence of compensatory mechanisms, whereby the loss of single fimbriae may modulate expression of other fimbriae or colonisation factors. In a murine model deletions in the $S$. Typhimurium $l p f$, pef, fim and csg operons only moderately impaired virulence when tested individually, whereas a mutant containing all four deletions exhibited a 26-fold increase in the median lethal dose and reduced ability to colonise the intestinal lumen [15]. Further studies with $S$. Enteritidis strains harbouring multiple fimbrial mutations may be warranted. Transcriptome analysis of the expression of fimbrial genes in the mutant strains described herein may indicate whether cross-talk and compensation mechanisms exist, provided probes are used that discriminate between fimbrial transcripts in the absence of cross-hybridisation.

\section{Conclusion}

$S$. Enteritidis phage type 4 possesses thirteen chromosomally-encoded fimbrial loci, from which the predicted major fimbrial subunits of the majority can be deleted without significantly impairing caecal colonisation of chickens. Our data support the involvement of Stb fimbriae, previously suggested by screening of signaturetagged mutants of $S$. Typhimurium in poultry, and reveal for the first time that PegA influences caecal colonisation of chickens by $S$. Enteritidis. Since StbA and PegA serve as antigens in mice and vaccination with a cocktail of purified fimbrial subunits is partially protective in a murine model [59], further studies are required to evaluate the efficacy of subunit or live-attenuated vaccines that exploit the data presented here for control of zoonotic S. enterica serovars in poultry.

\section{Authors' contributions}

DJC annotated and mutated the fimbrial loci, characterised each mutant in vivo and drafted the manuscript. AJB, $\mathrm{SDH}, \mathrm{AMB}$ and VLD provided valuable assistance to the chicken colonisation studies. NRT and MW supported bioinformatic analysis of the fimbrial operons and cosupervised DJC. PAB originally conceived the study. MPS led study design, data interpretation and manuscript revisions. EM and MJ provided a supervisory role.

\section{Additional material}

\section{Additional file 1}

Organisation of the fimbrial operons of S. Enteritidis P125109. The image shows the gene organisation of each of the fimbrial operons, the Pfam domains within the fimbrial operons and the \%GC content. Click here for file

[http://www.biomedcentral.com/content/supplementary/14712180-8-228-S1.doc]

\section{Additional file 2}

Conservation of the nucleotide sequences of S. Enteritidis strain P125019 genes across sequenced strains of other S. enterica serovars. The table provides the percent nucleotide identity of each fimbrial gene in several serovars of Salmonella compared with S. Enteritidis P125109. Click here for file

[http://www.biomedcentral.com/content/supplementary/14712180-8-228-S2.doc]

\section{Additional file 3}

3a. Dam methylase target sequence GATC within and proximal to $\mathrm{S}$. Enteritidis P125109 fimbrial operons. 3b. Putative homo-polymeric tracts in the S. Enteritidis P125109 genome sequence. The tables indicate regions of potential phase variable targets.

Click here for file

[http://www.biomedcentral.com/content/supplementary/14712180-8-228-S3.doc] 


\section{Additional file 4}

S. Enteritidis P125109 colonisation of Rhode Island Red Chickens at 1, 3 and 7 days post-infection. The graph shows the colonisation of S. Enteritidis P125109 at different organs within the chicken, at different times post-infection.

Click here for file

[http://www.biomedcentral.com/content/supplementary/14712180-8-228-S4.pdf]

\section{Acknowledgements}

The authors gratefully acknowledge funding via a CASE studentship from the Biotechnology \& Biological Sciences Research Council and Lohmann Animal Health Ltd., and the support of the Department for the Environment, Food \& Rural Affairs (grants OZ0319 and OZ0320). The authors wish to thank staff at the Experimental Animal House, IAH Compton, for technical assistance. Sequencing of the $S$. Enteritidis PI25I09 genome was supported via the Wellcome Trust Beowulf Genomics Initiative.

\section{References}

I. Voetsch AC, van Gilder TJ, Angulo FJ, Farley MM, Shallow S, Marcus R, Cieslak PR, Deneen VC, Tauxe RV, Emerging Infections Program FoodNet Working Group: FoodNet estimate of the burden of illness caused by non-typhoid Salmonella infections in the United States. Clin Infect Dis 2004, 38:S I 27-I 34.

2. Braden CR: Salmonella enterica serotype Enteritidis and eggs: a national epidemic in the United States. Clin Infect Dis 2006, 43:512-517.

3. Marcus R, Varma JK, Medus C, Boothe EJ, Anderson BJ, Crume T, Fullerton KE, Moore MR, White PL, Lyszkowicz E, Voetsch AC, Angulo FJ: Emerging Infections Program FoodNet Working Group. Re-assessment of risk factors for sporadic Salmonella serotype Enteritidis infections: a case-control study in five FoodNet Sites, 2002-2003. Epidemiol Infect 2007, 35:84-92.

4. Altekruse SF, Bauer N, Chanlongbutra A, DeSagun R, Naugle A, Schlosser W, Umholtz R, White P: Salmonella enteritidis in broiler chickens, United States, 2000-2005. Emerg Infect Dis 2006, 12:1848-1852.

5. Altekruse S, Koehler J, Hickman-Brenner F, Tauxe RV, Ferris K: A comparison of Salmonella enteritidis phage types from eggassociated outbreaks and implicated laying flocks. Epidemiol Infect 1993, I 10:17-22.

6. Patrick ME, Adcock PM, Gomez TM, Altekruse SF, Holland BH, Tauxe RV, Swerdlow DL: Salmonella enteritidis infections, United States, 1985-1999. Emerg Infect Dis 2004, 10:I.

7. Wallis TS, Barrow PA: Salmonella epidemiology and pathogenesis in food-producing animals. In Escherichia coli and Salmonella: Cellular and Molecular Biology [online] Edited by: Dougan G. Washington DC: ASM Press; Module 8.6.2.I.

8. Hensel M, Shea JE, Gleeson C, Jones MD, Dalton E, Holden DW: Simultaneous identification of bacterial virulence genes by negative selection. Science 1995, 269:400-403.

9. Shea JE, Hensel M, Gleeson C, Holden DW: Identification of a virulence locus encoding a second type III secretion system in Salmonella Typhimurium. Proc Natl Acad Sci USA 1996, 93:2593-2597.

10. Turner AK, Lovell MA, Hulme SD, Zhang-barber L, Barrow PA: Identification of Salmonella Typhimurium genes required for colonisation of the chicken alimentary tract and for virulence in newly hatched chicks. Infect Immun 1998, 66:2099-2 I06.

II. Tsolis RM, Townsend SM, Miao EA, Miller SI, Ficht TA, Adams LG, Baumler AJ: Identification of a putative Salmonella enterica serotype Typhimurium host range factor with homology to IpaH and YopM by signature-tagged mutagenesis. Infect Immun 1999, 67:6385-6393.

12. Morgan E, Campbell JD, Rowe SC, Bispham J, Stevens MP, Bowen AJ, Barrow PA, Maskell DJ, Wallis TS: Identification of host-specific colonisation factors of Salmonella enterica serovar Typhimurium. Mol Microbiol 2004, 54:994-10I0.
13. Lawley TD, Chan K, Thompson LJ, Kim CC, Govoni GR, Monack DM: Genome-wide screen for Salmonella genes required for longterm systemic infection of the mouse. PLoS Pathogens 2006, 2:ell.

14. Carnell SC, Bowen A, Morgan E, Maskell DJ, Wallis TS, Stevens MP: Role in virulence and protective efficacy in pigs of Salmonella enterica serovar Typhimurium secreted components identified by signature-tagged mutagenesis. Microbiol 2007, 153:1940-1952.

15. Velden AW Van der, Baumler AJ, Tsolis RM, Heffron F: Multiple fimbrial adhesins are required for full virulence of Salmonella Typhimurium in mice. Infect Immun 1998, 66:2803-2808.

16. Edwards RA, Schifferli DM, Maloy SR: A role for Salmonella fimbriae in intraperitoneal infections. Proc Natl Acad Sci USA 2000, 97:1258-1262.

17. Weening EH, Barker JD, Laarakker MC, Humphries AD, Tsolis RM, Baumler A): The Salmonella enterica serotype Typhimurium Ipf, bcf, stb, stc, std, and sth fimbrial operons are required for intestinal persistence in mice. Infect Immun 2005, 73:3358-3366.

18. Ledeboer NA, Frye JG, McClelland M, Jones BD: Salmonella enterica serovar Typhimurium requires the Lpf, Pef, and Tafi fimbriae for biofilm formation on HEp-2 tissue culture cells and chicken intestinal epithelium. Infect Immun 2006, 74:3I 56-3169.

19. Allen-Vercoe E, Woodward MJ: Colonisation of the chicken caecum by afimbriate and aflagellate derivatives of Salmonella enterica serotype Enteritidis. Vet Microbiol 1999, 69:265-275.

20. Allen-Vercoe E, Sayers AR, Woodward MJ: Virulence of Salmonella enterica serotype Enteritidis aflagellate and afimbriate mutants in a day-old chick model. Epidemiol Infect 1999, 1 22:395-402.

21. Allen-Vercoe E, Woodward MJ: The role of flagella, but not fimbriae, in the adherence of Salmonella enterica serotype Enteritidis to chick gut explant. J Med Microbiol 1999, 48:77I-780.

22. Thorns CJ, Turcotte C, Gemmell CG, Woodward MJ: Studies into the role of the SEFI 4 fimbrial antigen in the pathogenesis of Salmonella enteritidis. Microb Pathog 1996, 20:235-246.

23. Rajashekara G, Munir S, Alexeyev MF, Halvorson DA, Wells CL, Nagaraja KV: Pathogenic role of SEF I4, SEF I7, and SEF2 I fimbriae in Salmonella enterica serovar Enteritidis infection of chickens. Appl Environ Microbiol 2000, 66:1759-1763.

24. De Buck J, van Immerseel F, Haesebrouck F, Ducatelle R: Effect of type I fimbriae of Salmonella enterica serotype Enteritidis on bacteraemia and reproductive tract infection in laying hens. Avian Pathol 2004, 33:314-320.

25. Cogan TA, Jørgensen F, Lappin-Scott HM, Benson CE, Woodward MJ, Humphrey TJ: Flagella and curli fimbriae are important for the growth of Salmonella enterica serovars in hen eggs. Microbiol 2004, 150: 1063-1071.

26. Thomson NR, Clayton DJ, Windhorst D, Vernikos G, Davidson S, Churcher C, Quail MA, Stevens M, Jones MA, Watson M, Barron A Layton A, Pickard D, Kingsley RA, Bignell A, Clark L, Harris B, Ormond D, Abdellah Z, Brooks K, Cherevach I, Chillingworth T, Woodward J, Norberczak H, Lord A, Arrowsmith C, Jagels K, Moule S, Mungall K, Saunders M, Whitehead S, Chabalgoity JA, Maskell D, Humphreys T, Roberts M, Barrow PA, Dougan G, Parkhill J: Comparative genome analysis of Salmonella Enteritidis PT4 and Salmonella Gallinarum 287/9 I provides insights into evolutionary and host adaptation pathways. Genome Res 2008, 18:1624-1637.

27. Nuccio SP, Baumler A): Evolution of the chaperone/usher assembly pathway: fimbrial classification goes Greek. Microbiol Mol Biol Rev 2007, 7 I:55 I-575.

28. Datsenko KA, Wanner BL: One-step inactivation of chromosomal genes in Escherichia coli K-I 2 using PCR products. Proc Natl Acad Sci USA 2000, 97:6640-6645.

29. McClelland M, Sanderson KE, Spieth J, Clifton SW, Latreille P, Courtney L, Porwollik S, Ali J, Dante M, Du F, Hou S, Layman D, Leonard S, Nguyen C, Scott K, Holmes A, Grewal N, Mulvaney E, Ryan E, Sun H, Florea L, Miller W, Stoneking T, Nhan M, Waterston R, Wilson RK: Complete genome sequence of Salmonella enterica serovar Typhimurium LT2. Nature 2001, 4 I3:852-856.

30. Parkhill J, Dougan G, James KD, Thomson NR, Pickard D, Wain J, Churcher C, Mungall KL, Bentley SD, Holden MT, Sebaihia M, Baker S, Basham D, Brooks K, Chillingworth T, Connerton P, Cronin A, Davis P, Davies RM, Dowd L, White N, Farrar J, Feltwell T, Hamlin N, 
Haque A, Hien TT, Holroyd S, Jagels K, Krogh A, Larsen TS, Leather S, Moule S, O'Gaora P, Parry C, Quail M, Rutherford K, Simmonds M, Skelton J, Stevens K, Whitehead S, Barrell BG: Complete genome sequence of a multiple drug resistant Salmonella enterica serovar Typhi CT I 8. Nature 200I, 4I 3:848-852.

31. Deng W, Liou SR, Plunkett G 3rd, Mayhew GF, Rose DJ, Burland V, Kodoyianni V, Schwartz DC, Blattner FR: Comparative genomics of Salmonella enterica serovar Typhi strains Ty2 and CTI8. J Bacteriol 2003, I85:2330-2337.

32. Chiu CH, Tang P, Chu C, Hu S, Bao Q, Yu J, Chou YY, Wang HS, Lee YS: The genome sequence of Salmonella enterica serovar Choleraesuis, a highly invasive and resistant zoonotic pathogen. Nucl Acids Res 2005, 33:1690-1698.

33. Carver TJ, Rutherford KM, Berriman M, Rajandream MA, Barrell BG, Parkhill J: ACT: the Artemis Comparison Tool. Bioinformatics 2005, $21: 3422-3423$.

34. Rutherford K, Parkhill J, Crook J, Horsnell T, Rice P, Rajandream MA, Barrell B: Artemis: sequence visualization and annotation. Bioinformatics 2000, 16:944-945.

35. Benson G: Tandem repeats finder: a program to analyze DNA sequences. Nucl Acids Res 1999, 27:573-580.

36. Cherepanov PP, Wackernagel W: Gene disruption in Escherichia coli: TcR and $\mathrm{KmR}$ cassettes with the option of Flp-catalyzed excision of the antibiotic-resistance determinant. Gene 1995 I58:9-14.

37. Chang AC, Cohen SN: Construction and characterization of amplifiable multicopy DNA cloning vehicles derived from the P I 5A cryptic miniplasmid. | Bacteriol | 978, | 34: | |4|-| | 56.

38. Nurmi E, Rantala M: New aspects of Salmonella infection in broiler production. Nature 1973, 241:210-2II.

39. Hammar M, Bian Z, Normark S: Nucleator-dependent intercellular assembly of adhesive curli organelles in Escherichia coli. Proc Natl Acad Sci USA 1996, 93:6562-6566.

40. Salih O, Remaut H, Waksman G, Orlova EV: Structural analysis of the saf pilus by electron microscopy and image processing. J Mol Biol 2008, 379: 174-I87.

41. Abraham JM, Freitag CS, Clements JR, Eisenstein BI: An invertible element of DNA controls phase variation of type I fimbriae of Escherichia coli. Proc Natl Acad Sci USA 1985, 82:5724-5727.

42. Blyn LB, Braaten BA, Low DA: Regulation of pap pilin phase variation by a mechanism involving differential dam methylation states. EMBO ] 1990, 9:4045-4054.

43. Meyer TF, van Putten JP: Genetic mechanisms and biological implications of phase variation in pathogenic neisseriae. Clin Microbiol Rev 1989, 2:SI39-145.

44. Old DC, Corneil I, Gibson LF, Thomson AD, Duguid JP: Fimbriation, pellicle formation and the amount of growth of salmonellas in broth. J Gen Microbiol I968, $51: 1-16$.

45. Old DC, Duguid JP: Selective outgrowth of fimbriate bacteria in static liquid medium. J Bacteriol | 970, 103:447-445.

46. Swenson DL, Clegg S: Identification of ancillary fim genes affecting fimA expression in Salmonella typhimurium. J Bacteriol I992, 174:7697-7704.

47. Norris TL, Kingsley RA, Baumler AJ: Expression and transcriptional control of the Salmonella typhimurium Ipf fimbrial operon by phase variation. Mol Microbiol 1998, 29:3 I -320.

48. Nicholson B, Low D: DNA methylation-dependent regulation of pef expression in Salmonella typhimurium. Mol Microbiol 2000, 35:728-742.

49. Balbontin R, Rowley G, Pucciarelli MG, Lopez-Garrido J, Wormstone Y, Lucchini S, Garcia-Del Portillo F, Hinton JC, Casadesus J: DNA adenine methylation regulates virulence gene expression in Salmonella enterica serovar Typhimurium. J Bacteriol 2006, I88:8160-8168.

50. Chessa D, Winter MG, Nuccio SP, Tükel C, Bäumler AJ: RosE represses Std fimbrial expression in Salmonella enterica serotype Typhimurium. Mol Microbiol 2008, 68:573-587.

51. Suar M, Jantsch J, Hapfelmeier S, Kremer M, Stallmach T, Barrow PA, Hardt W-D: Virulence of broad- and narrow-host-range Salmonella enterica serovars in the streptomycin-pretreated mouse model. Infect Immun 2006, 74:632-644.

52. Fanelli MJ, Sadler WW, Franti CE, Brownell JR: Localization of Salmonellae within the intestinal tract of chickens. Avian Dis 1971, 15:366-375.

53. Barrow PA, Simpson JM, Lovell MA: Intestinal colonisation in the chicken by food poisoning Salmonella serotypes; microbial characteristics associated with faecal excretion. Avian Pathol 1988, 17:57I-588.

54. Knodler LA, Bestor A, Ma C, Hansen-Wester I, Hensel M, Vallance $\mathrm{BA}$, Steele-Mortimer O: Cloning vectors and fluorescent proteins can significantly inhibit Salmonella enterica virulence in both epithelial cells and macrophages: implications for bacterial pathogenesis studies. Infect Immun 2005, 73:7027-703I.

55. Porwollik S, Santiviago CA, Cheng P, Florea L, McClelland M: Differences in gene content between Salmonella enterica serovar Enteritidis isolates and comparison to closely related serovars Gallinarum and Dublin. J Bacteriol 2005, 187:6545-6555.

56. Porwollik S, Boyd EF, Choy C, Cheng P, Florea L, Proctor E, McClelland M: Characterization of Salmonella enterica subspecies I genovars by use of microarrays. J Bacteriol 2004, 186:5883-5898.

57. Anjum MF, Marooney C, Fookes M, Baker S, Dougan G, Ivens A Woodward MJ: Identification of core and variable components of the Salmonella enterica subspecies I genome by microarray. Infect Immun 2005, 73:7894-7905.

58. Humphries AD, Raffatellu M, Winter S, Weening EH, Kingsley RA, Droleskey R, Zhang S, Figueiredo J, Khare S, Nunes J, Adams LG, Tsolis RM, Bäumler AJ: The use of flow cytometry to detect expression of subunits encoded by II Salmonella enterica serotype Typhimurium fimbrial operons. Mol Microbiol 2003, 48:1357-1376.

59. Humphries A, Deridder S, Bäumler AJ: Salmonella enterica serotype Typhimurium fimbrial proteins serve as antigens during infection of mice. Infect Immun 2005, 73:5329-5338.
Publish with BioMed Central and every scientist can read your work free of charge

"BioMed Central will be the most significant development for disseminating the results of biomedical research in our lifetime. "

Sir Paul Nurse, Cancer Research UK

Your research papers will be:

- available free of charge to the entire biomedical community

- peer reviewed and published immediately upon acceptance

- cited in PubMed and archived on PubMed Central

- yours - you keep the copyright

Submit your manuscript here:

http://www.biomedcentral.com/info/publishing_adv.asp
BioMedcentral 